Tropical Journal of Pharmaceutical Research October 2019; 18 (10): 2175-2182

ISSN: $1596-5996$ (print); 1596-9827 (electronic)

(c) Pharmacotherapy Group, Faculty of Pharmacy, University of Benin, Benin City, 300001 Nigeria.

Available online at http://www.tjpr.org

http://dx.doi.org/10.4314/tjpr.v18i10.25

Original Research Article

\title{
A UHPLC-Q-Exactive-Orbitrap-MS method for simultaneous determination of three flavonoids from Parasitic loranthus and their pharmacokinetics in rat plasma
}

\author{
Ying Cui ${ }^{1,2}$, Lingling $\mathrm{Li}^{1,2 \star}$, Shu Yang ${ }^{1}$, Hongli Wang ${ }^{1}$, Jing Feng ${ }^{1}$, Kai $\mathrm{Ma}^{3}$, Deen \\ Han $^{1}$ \\ ${ }^{1}$ School of Pharmacy, Henan University of Chinese Medicine, Zhengzhou, ${ }^{2}$ Collaborative Innovation Center for Respiratory \\ Disease Diagnosis and Treatment \& Chinese Medicine Development of Henan Province, 156 Jinshui East Road, Zhengzhou \\ 450046, ${ }^{3}$ Henan Province Chinese Medicine Research Institute, Zhengzhou, China
}

*For correspondence: Email: cyexin@126.com, openliling@163.com

Sent for review: 29 December 2018

Revised accepted: 18 September 2019

\begin{abstract}
Purpose: To develop and validate a chromatographic method for the simultaneous determination of plasma levels of rutin, avicularin and quercitrin using UHPLC-Q-Exactive-Orbitrap-MS.

Methods: A sensitive, selective, and reliable UHPLC-Q-Exactive-Orbitrap-MS method was developed and validated for simultaneous determination of the three flavonoids, with puerarin as internal standard (IS). Plasma samples were first treated with methanol, and then acidified using hydrochloric acid ( $\mathrm{HCl}$ ) prior to liquid-liquid extraction with ethyl acetate. The flavonoids were separated on a Syncronis C18 column $(100 \times 2.1 \mathrm{~mm}, 1.7 \mu \mathrm{m})$ using an elution gradient of acetonitrile and $0.1 \%$ formic acid at a flow rate of $0.3 \mathrm{~mL} / \mathrm{min}$.

Results: A linear correlation was obtained for the three flavonoids over the investigated concentration range, with correlation coefficients $>0.9954$. The values of validated lower limit of quantification (LLOQ) were $0.68,1.42$ and $2.54 \mathrm{ng} / \mathrm{mL}$ for rutin, avicularin and quercitrin, respectively. Intra- and inter-day precision (RSD) were $<10 \%$, while accuracy (RE) ranged from -3.76 to $4.04 \%$.

Conclusion: The proposed method has been successfully validated and is suitable for studying the pharmacokinetics of the three analytes in rats treated with parasitic loranthus extract (PLE).
\end{abstract}

Keywords: Parasitic loranthus, Rutin, Avicularin, Quercitrin, UHPLC-Q-Exactive-Orbitrap-MS, Pharmacokinetics

\begin{abstract}
This is an Open Access article that uses a fund-ing model which does not charge readers or their institutions for access and distributed under the terms of the Creative Commons Attribution License (http://creativecommons.org/licenses/by/4.0) and the Budapest Open Access Initiative (http://www.budapestopenaccessinitiative.org/read), which permit unrestricted use, distribution, and reproduction in any medium, provided the original work is properly credited.

Tropical Journal of Pharmaceutical Research is indexed by Science Citation Index (SciSearch), Scopus, International Pharmaceutical Abstract, Chemical Abstracts, Embase, Index Copernicus, EBSCO, African Index Medicus, JournalSeek, Journal Citation Reports/Science Edition, Directory of Open Access Journals (DOAJ), African Journal Online, Bioline International, Open-J-Gate and Pharmacy Abstracts
\end{abstract}

\section{INTRODUCTION}

Sang $j i$ sheng, the branches and leaves of parasitic loranthus, is a traditional Chinese medicine which was known in "Shennong's
Herbal" eighteen hundreds years ago [1]. As far as is known, loranthus is a semi-parasitic plant, but the growth environment of the host trees varies widely [2]. The quality of medicinal parasitic loranthus is affected by the nature of the 
host tree. These qualities include content of bioactive components and the efficacy of the drug. Therefore, studies on the parasitic nature of the relationship between loranthaceae and its host have continued to engage the attention of researchers [3-7].

In China, parasitic loranthus is widely used in many types of traditional Chinese medicinal prescriptions (TCMPs) for the treatment of soreness, threatened abortion, rheumatism and intractable dizziness [1]. Pharmacological studies demonstrate that parasitic loranthus exerts several pharmacological effects such as inhibition of fatty acid synthase and enhancement of weight loss [8]; diuretic and hypotensive effects $[9,10]$, antidiabetic effects $[11,12]$, and protective effects on learning and memory abilities [13]. Some reports show that the parasitic loranthus which is also named Taxillus, is rich in flavonoids [14,15], as well as hemiterpenoid derivatives [16].

Although the pharmacological and chemical properties of parasitic loranthus have attracted much research attention, not much is known about its pharmacokinetics. This study attempted to provide a new approach for determination of the bioactive components of parasitic loranthus in plasma, in order to characterize its pharmacokinetics. In previous studies, researchers found that the anti-rheumatic and anti-osteoporotic substances in loranthus were mainly flavonoids such as rutin, avicularin and quercitrin $[17,18]$. Rutin is one of the most active flavonoids, and it has been reported that it relieved pain and intra-ocular pressure when combined with vitamin C [19]. Avicularin and quercetin are potent inhibitors of fatty acid synthase [20]. Thus, it would be helpful to develop an approach which can be used for simultaneous determination of these three flavonoids. The UHPLC-MS/MS method provides high sensitivity and selectivity, and can be used for microanalysis of multi-components [21]. In recent years, it has been rapidly developed into an important method for measuring the composition of trace components in food and drugs [22-26]. The present study was carried out to determine the pharmacokinetics of rutin, avicularin and quercitrin in rats.

\section{EXPERIMENTAL}

\section{Materials and reagents}

Dried parasitic loranthus was purchased from Zhang Zhongjing Pharmacy, Henan, China. It was authenticated by Professor Suiqing Chen and Chengming Dong at Henan University of
Chinese Medicine. Rutin, avicularin, and quercitrin were purchased from Sichuang Vicket Company (Chengdu, China). Puerarin was supplied by China Research Institute of Food and Drug Verification (Beijing, China). The structures of the three flavonoids and puerarin are shown in Figure 2. Heparin sodium, sodium carboxymethylcellulose (CMC-Na) and formic acid were supplied by Sigma-Aldrich (St. Louis, USA). Acetonitrile and methanol were purchased from Thermo Fisher. Hydrochloric acid and ethyl acetate obtained from Tianjin Dasen Chemical Products Sales Company, Tianjin, China.

A pressurized fluid extract (PLE) was prepared. The dried parasitic loranthus $(500 \mathrm{~g})$ was extracted twice with $70 \%$ ethanol. The extract was concentrated to $0.08 \mathrm{~g} / \mathrm{mL}$, and subjected to separation and purification using elution through AB-8 macroporous adsorption resin. First, distilled water was used to elute the column, followed by elution with $50 \%$ ethanol. The $50 \%$ ethanol eluate was finally vacuum-dried to obtain a flavonoid-enriched extract $(27.5 \mathrm{~g})$. The flavonoid-enriched extract was subjected to HPLC analysis for determination of the contents of the three flavonoids. The results showed that the levels of rutin, avicularin and quercitrin in the PLE were $0.87,1.10$ and $3.74 \%$, respectively.

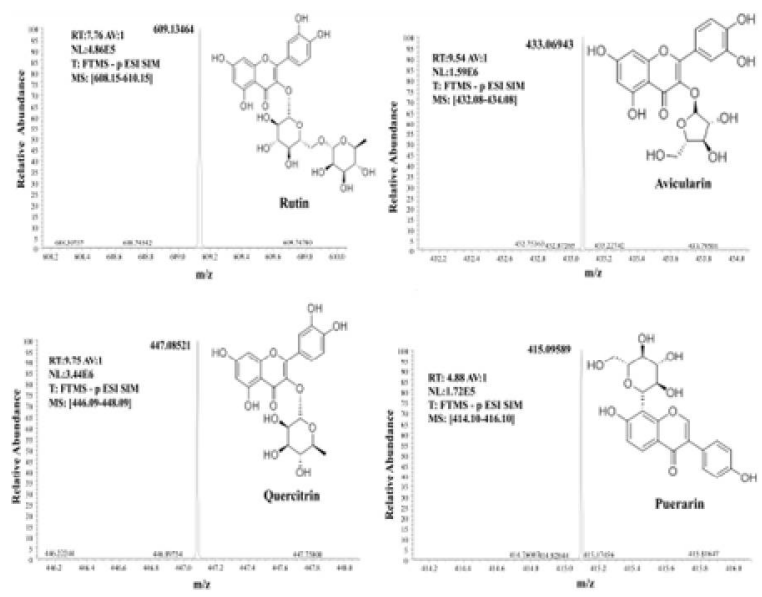

Figure 1: Molecular mass and structures of the analytes and IS in negative electrospray ionization mode

\section{UHPLC-Q-Exactive-Orbitrap-MS instrument settings}

Chromatographic analysis was performed using Thermo UPLC System. Syncronis $\mathrm{C}_{18}$ column was used at $30{ }^{\circ} \mathrm{C}$, and a gradient elution with water containing $0.1 \%$ formic acid (A) and acetonitrile (B) was used at a flow rate of 0.30 $\mathrm{mL} / \mathrm{min}$ as follows: $0-11 \mathrm{~min}$ with $14-42 \% \mathrm{~B}$; $11-11.2$ min with $42-14 \% \mathrm{~B}$, and $11.2-14.2$ min with $14 \% \mathrm{~B}$. 
Mass spectrometric analysis was performed with Thermo Q-Exactive -Qibitrap-MS under the following conditions: voltage of $2.8 \mathrm{kV}, 40$ units of sheath gas flow, 10 units of auxiliary gas flow, nitrogen flow rate of $10 \mathrm{~mL} / \mathrm{min}$, and temperature of $350{ }^{\circ} \mathrm{C}$.

\section{Calibration standards and quality control samples}

Rutin, avicularin and quercitrin standards were dissolved in $10 \mathrm{~mL}$ of methanol to obtain standard solutions of concentrations 43.2, 91.2 and $162.4 \mu \mathrm{g} / \mathrm{mL}$. The internal standard (IS) solution and working standard solution of IS were prepared in methanol. Calibration standard samples and quality control (QC) samples were prepared by spiking blank rat plasma with moderate working solutions. They were extracted using the same procedures for plasma samples.

\section{Sample preparation}

A liquid-liquid extraction (LLE) method was used to extract the three analytes and IS from rat plasma. All protocols in animal experiments were approved by the Ethics Committee on Animal Research of Henan University of Chinese Medicine (approval ref. No: HNUTCMEKY201800361Z), and were carried out in line with the guidelines of the Committee on the Care and Use of Laboratory Animals in China [27]. The plasma was spiked with $100 \mu \mathrm{L}$ of IS and $50 \mu \mathrm{L}$ of $0.25 \mathrm{M} \mathrm{HCl}$, and vortexed for $1 \mathrm{~min}$. The proteins were precipitated by addition of $200 \mu \mathrm{L}$ methanol. Thereafter, the mixture was extracted with $1 \mathrm{~mL}$ ethyl acetate through oscillation for 5 $\mathrm{min}$ at room temperature, followed by centrifugation at $12000 \mathrm{rpm}$ for $5 \mathrm{~min}$. The extract was then transferred to a clean tube and evaporated to dryness under mild nitrogen at 40 ${ }^{\circ} \mathrm{C}$. The resultant residue was dissolved in methanol.

\section{Validation of method}

The method was validated with respect to selectivity, matrix effect, recovery, linearity, precision, accuracy and stability, in line with the FDA guidelines for validation of bioanalytical methods.

\section{Linearity and quantification}

Linear interpolation from the calibration curves was used for calculating the concentrations of the flavonoids in all samples, while LLOQ was used for determination of the lowest concentrations.

\section{Selectivity, matrix effect and recovery}

The selectivity was assessed by analyzing 6 blank plasma samples (from different rats) which were spiked with rutin, avicularin, quercitrin and IS, and rat plasma sample treated with PLE (400 $\mathrm{mg} / \mathrm{kg}$ ) for $60 \mathrm{~min}$.

The extraction recoveries and matrix effects of the analytes were performed as described by Sun [28]. When the ratios $[(A / B \times 100) \%]$ of the analytes and IS solution ranged from 85 to 115 $\%$, the matrix effect was negligible.

\section{Precision, accuracy and stability}

The precision, accuracy and stability were determined according to the method described by Sun [28].

\section{Pharmacokinetic studies}

Six Sprague-Dawley rats (weighing $200 \pm 20 \mathrm{~g}$ ) were obtained from Henan Experimental Animal Center (Zhengzhou, China; certificate No: SCXK 2015-0004). All protocols of animal experiments received approval from the Ethics Committee of Animal Research, Henan University of Chinese Medicine (approval ref. No: HNUTCMEKY201800361Z). The rats were fed in an environment with temperature of $25{ }^{\circ} \mathrm{C}$, relative humidity of $60 \%$, under 12-h light/12-h dark cycle for 7 days. Prior to PLE administration, the rats were fasted for $12 \mathrm{~h}$, but were allowed free access to clean drinking water. They were then given single oral administration of PLE (400 $\mathrm{mg} / \mathrm{kg}$ ) dissolved in $0.5 \% \mathrm{CMC}-\mathrm{Na}$. Blood samples were collected in heparinized hemostasia tubes $5,10,15,30,45,60,90,120$, $180,240,360$, and $540 \mathrm{~min}$ after oral administration of PLE. The blood samples were centrifuged, and the plasma samples were kept frozen at $-20^{\circ} \mathrm{C}$ prior to analysis.

\section{Chromatography and mass spectrometry}

Various mobile phase conditions were tried in this study. Methanol, acetonitrile, $0.1 \%$ formic acid and water, and their combinations were tested as mobile phases. Finally, a gradient elution with acetonitrile and water containing $0.1 \%$ formic acid was selected for optimal peak symmetry, good resolution, and significantly enhanced sensitivity. Total chromatographic analysis was conducted in $11 \mathrm{~min}$, with retention times of $7.76 \mathrm{~min}$ for rutin, $9.54 \mathrm{~min}$ for avicularin, $9.75 \mathrm{~min}$ for quercitrin, and $4.90 \mathrm{~min}$ for the IS.

In mass spectrometry (MS), it was found that 
Target-SIM mode was best for collecting the molecular ion peaks.

\section{Statistical analysis}

All data are presented as mean \pm standard deviation (SD). Relevant pharmacokinetic parameters were calculated using DAS3.0 software.

\section{RESULTS}

\section{Selectivity, matrix effect, recovery}

Selectivity was calculated through comparison of typical chromatograms of blank plasma (A), blank plasma spiked with rutin $(10.8 \mathrm{ng} / \mathrm{mL})$, avicularin $(45.6 \mathrm{ng} / \mathrm{mL})$, quercitrin $(81.2 \mathrm{ng} / \mathrm{mL})$, puerarin $(25.0 \mathrm{ng} / \mathrm{mL})(B)$, and plasma sample after oral administration of the PLE for $60 \mathrm{~min}$ (C), as shown in Figure 2. The retention times for rutin, avicularin, quercitrin and puerarin (internal standard) were 7.76, 9.54, 9.75 and $4.90 \mathrm{~min}$, respectively. No endogenous interference was observed in full scan mode for each analyte.

In order to effectively remove the interference of the matrix from the analytical results, matrix effect and extraction recovery were determined, and data for all analytes are shown in Table 1. The ratios ranged from $87.79-101.61 \%$, and for IS, the ratio was $94.23 \%$. These results suggest that absence of endogenous substances and interference in the co-eluting matrix. The extraction recoveries ranged from 86.08 $106.64 \%$, which were within acceptable range.

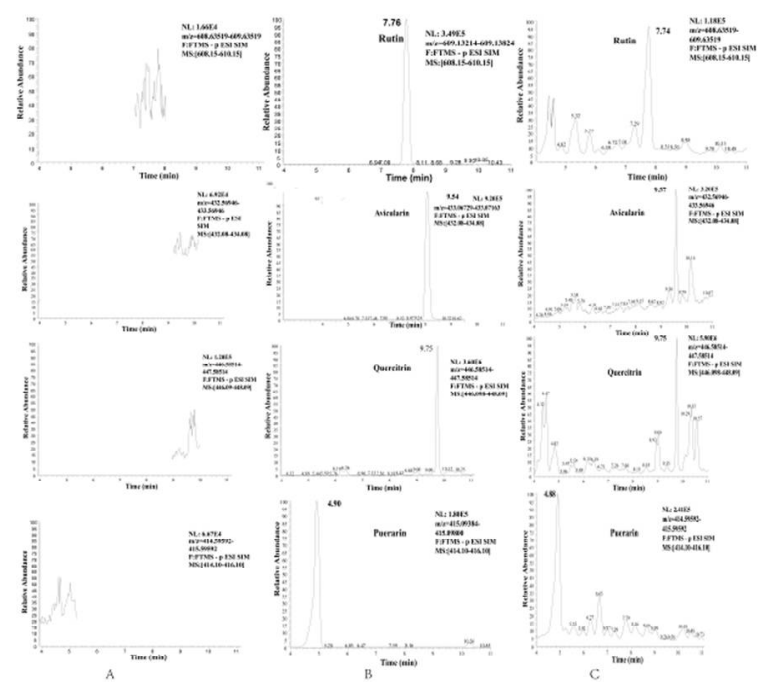

Figure 2: Representative chromatograms of the three analytes and IS in rat plasma. (A) Blank plasma, (B) blank plasma spiked with rutin, avicularin, quercitrin and the IS, and (C) rat plasma sample after oral administration of PLE $(400 \mathrm{mg} / \mathrm{kg})$ for $60 \mathrm{~min}$

\section{Linearity and the lower limits of quantitation (LLOQ)}

Linear correlation was seen in the concentration ranges of $0.68-43.20 \mathrm{ng} / \mathrm{mL}$ for rutin, 1.42 $91.20 \mathrm{ng} / \mathrm{mL}$ for avicularin, and $2.54-162.40$ $\mathrm{ng} / \mathrm{mL}$ for quercitrin. Linear regressions of the peak area ratios versus concentrations for these analytes in rat plasma are shown in Table 2. The LLOQ for rutin, avicularin and quercitrin were $0.68,1.42$, and $2.54 \mathrm{ng} / \mathrm{mL}$, respectively.

Table 1: Matrix effects and extraction recovery of analytes from rat plasma $(n=6)$

\begin{tabular}{lccc}
\hline Analyte & $\begin{array}{c}\text { Spiked } \\
\text { concentration } \\
(\mathbf{n g} / \mathbf{m L})\end{array}$ & $\begin{array}{c}\text { Matrix effect } \\
\text { (mean } \pm \text { SD, } \%)\end{array}$ & $\begin{array}{c}\text { Extraction recovery } \\
\text { (mean } \pm \text { SD, \%) }\end{array}$ \\
\hline Rutin & 2.70 & $96.82 \pm 3.87$ & $101.91 \pm 3.71$ \\
Avicularin & 10.80 & $90.39 \pm 6.87$ & $93.40 \pm 2.36$ \\
& 21.60 & $91.85 \pm 3.10$ & $106.64 \pm 5.63$ \\
Quercitrin & 5.70 & $97.08 \pm 4.25$ & $101.78 \pm 3.30$ \\
& 22.80 & $96.91 \pm 4.21$ & $87.28 \pm 6.28$ \\
& 45.60 & $92.43 \pm 1.66$ & $94.97 \pm 4.83$ \\
& 10.15 & $87.79 \pm 8.56$ & $86.08 \pm 7.87$ \\
& 40.60 & $101.61 \pm 2.65$ & $99.31 \pm 2.48$ \\
& 81.20 & $93.96 \pm 2.64$ & $99.98 \pm 1.90$ \\
\hline
\end{tabular}

Table 2: Regression equations for calibration curves and LLOQ

\begin{tabular}{llccc}
\hline Analyte & $\mathbf{y}=\mathbf{a x + b}$ & Linear range $(\mathbf{n g} / \mathbf{m L})$ & $\mathbf{R 2}$ & $\mathbf{L L O Q}(\mathbf{n g} / \mathbf{m L})$ \\
\hline Rutin & $\mathrm{y}=0.0659 x+0.0564$ & $0.68-43.20$ & 0.9986 & 0.68 \\
Avicularin & $\mathrm{y}=0.0592 \mathrm{x}+0.0648$ & $1.42-91.20$ & 0.9954 & 1.42 \\
Quercitrin & $\mathrm{y}=0.2180 \mathrm{x}+0.2015$ & $2.54-162.40$ & 0.9989 & 2.54
\end{tabular}


Table 3: Precision and accuracy for analytes in rat plasma $(n=6)$

\begin{tabular}{|c|c|c|c|c|c|c|c|}
\hline \multirow[t]{2}{*}{ Analyte } & \multirow{2}{*}{$\begin{array}{c}\text { Spiked } \\
\text { concentra- } \\
\text { tion } \\
(\mathrm{ng} / \mathrm{mL})\end{array}$} & \multicolumn{3}{|c|}{ Intra-day } & \multicolumn{3}{|c|}{ Inter-day } \\
\hline & & $\begin{array}{l}\text { Measured } \\
\text { Concentra- } \\
\text { tion (ng/mL) }\end{array}$ & $\begin{array}{l}\text { Precision } \\
\text { (\% RSD) }\end{array}$ & $\begin{array}{c}\text { Accuracy } \\
\text { (\% RE) }\end{array}$ & $\begin{array}{l}\text { Measured } \\
\text { Concentra- } \\
\text { tion (ng/mL) }\end{array}$ & $\begin{array}{l}\text { Precision } \\
\text { (\% RSD) }\end{array}$ & $\begin{array}{c}\text { Accuracy } \\
\text { (\% RE) }\end{array}$ \\
\hline \multirow[t]{3}{*}{ Rutin } & 2.70 & $2.76 \pm 0.05$ & 1.82 & 2.35 & $2.75 \pm 0.04$ & 1.61 & 1.98 \\
\hline & 10.80 & $10.58 \pm 0.18$ & 1.68 & -2.04 & $10.58 \pm 0.14$ & 1.33 & -2.01 \\
\hline & 21.60 & $22.13 \pm 0.67$ & 3.01 & 2.47 & $22.33 \pm 0.63$ & 2.84 & 3.40 \\
\hline \multirow[t]{3}{*}{ Avicularin } & 5.70 & $5.78 \pm 0.37$ & 6.32 & 1.40 & $5.79 \pm 0.33$ & 5.69 & 1.54 \\
\hline & 22.80 & $22.08 \pm 1.05$ & 4.77 & -3.17 & $22.06 \pm 0.91$ & 4.11 & -3.24 \\
\hline & 45.60 & $44.38 \pm 1.96$ & 4.41 & -2.67 & $44.76 \pm 1.31$ & 2.93 & -1.84 \\
\hline \multirow[t]{3}{*}{ Quercitrin } & 10.15 & $10.56 \pm 0.96$ & 9.10 & 4.04 & $10.51 \pm 0.87$ & 8.29 & 3.57 \\
\hline & 40.60 & $39.42 \pm 1.02$ & 2.59 & -2.91 & $39.21 \pm 1.11$ & 2.84 & -3.42 \\
\hline & 81.20 & $78.15 \pm 4.29$ & 5.49 & -3.76 & $78.48 \pm 3.89$ & 4.96 & -3.36 \\
\hline
\end{tabular}

Table 4: Stability of the analytes in rat plasma under different storage conditions $(n=6)$

\begin{tabular}{|c|c|c|c|c|c|c|c|c|c|}
\hline \multirow[t]{2}{*}{ Analyte } & \multirow{2}{*}{$\begin{array}{c}\text { Spiked } \\
\text { concen- } \\
\text { tration } \\
(\mathrm{ng} / \mathrm{mL})\end{array}$} & \multicolumn{2}{|c|}{$\begin{array}{c}\text { Room temperature } \\
\text { for } 8 \mathrm{~h} \\
\end{array}$} & \multicolumn{2}{|c|}{$\begin{array}{c}4{ }^{\circ} \mathrm{C} \text { temperature } \\
\text { for } 24 \mathrm{~h}\end{array}$} & \multicolumn{2}{|c|}{$\begin{array}{l}\text { Three freeze-thaw } \\
\text { cycles at }-20 \circ \mathrm{C}\end{array}$} & \multicolumn{2}{|c|}{$\begin{array}{l}\text { Frozen at }-20^{\circ} \mathrm{C} \\
\text { for } 30 \text { days }\end{array}$} \\
\hline & & Mean \pm SD & RE (\%) & Mean \pm SD & RE (\%) & Mean \pm SD & RE (\%) & Mean \pm SD & RE (\%) \\
\hline \multirow[t]{3}{*}{ Rutin } & 2.7 & 2 & & 2.6 & & & 1. & & 1.8 \\
\hline & 10. & & & & & & & & -4.2 \\
\hline & 21. & & & 22.91 & & & & 22. & 5.4 \\
\hline \multirow[t]{3}{*}{ Avicularin } & 5.70 & 5.7 & 1. & $5.65=$ & -1 & & -1 & 5.8 & 1.9 \\
\hline & 22.80 & 22. & 0 & 21.1 & -7 & & & 20 & -8.8 \\
\hline & 45.60 & $44.25 \pm 2.36$ & -3. & $44.08=$ & -3 & 44.8 & -1 & 45.7 & 0.3 \\
\hline \multirow[t]{3}{*}{ Quercitrin } & 10.15 & $9.92 \pm 0.8$ & -2.3 & $10.10 \pm 1.24$ & -0 & 9.9 & -2 & 10.0 & -1.4 \\
\hline & 40.60 & $41.63 \pm 1.3$ & 2.5 & $41.44 \pm 2.38$ & 2. & 41.9 & 3. & $42.22 \pm 3$ & 4.0 \\
\hline & 81.20 & $80.20 \pm 3.75$ & -1.2 & $78.87 \pm 5.46$ & -2.9 & $79.03 \pm 5.63$ & -2.7 & $79.24 \pm 5.92$ & -2.4 \\
\hline
\end{tabular}

\section{Precision and accuracy}

Data associated with precision and accuracy of the three analytes in QC samples are presented in Table 3. The results indicate that the intra- and inter-day precision (RSD) of these analytes ranged from 1.61 to $9.10 \%$, while the corresponding REs ranged from -3.76 to $4.04 \%$. These data demonstrate that the precision and accuracy achieved with this method were acceptable.

\section{Stability}

The stability of the three analytes in different conditions are presented in Table 4. The extracted samples were stable under all test conditions, which demonstrates that the samples were stable in typical conditions of conventional pharmacokinetic analysis of the three flavonoids.

Plasma concentration-time profiles for the three flavonoids

The average plasma concentration-time curves of the 3 flavonoids are shown in Figure 3 . The area under curve (AUC), mean resident time
(MRT), half-life $\left(t_{1 / 2}\right)$, peak time $\left(T_{\max }\right)$, and maximum plasma concentration $\left(\mathrm{C}_{\max }\right)$ were estimated using DAS3.0 software.

\section{Pharmacokinetics of the three flavonoids}

The main pharmacokinetic parameters of the three flavonoids are shown in Table 5.

\section{DISCUSSION}

Mulberry parasitic is the dry stalk of the mulberry parasitic plant which is used for treatment of rheumatism, weak bones and threatened miscarriage. It is clinically used for rheumatic pain, weak waist and knees, weak bones, and fetal dysphoria. Modern research has found that the chemical components contained in mulberry parasitic are mainly flavonoids, alkaloids, anthraquinones, organic acids, polysaccharides, proteins and lectins, with quercetin, rutin and avicularin as the major flavonoids.

The new method developed in this study was successfully applied in the determination of the concentrations of the three flavonoids after rats 

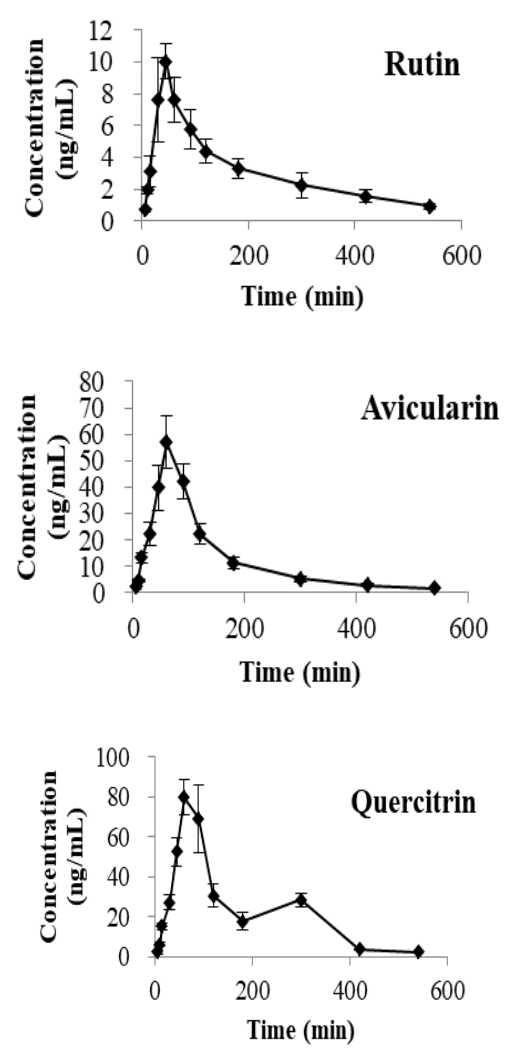

Figure 3: Plasma concentration-time curves of rutin, avicularin, quercitrin after oral administration of parasitic loranthus extract $(n=6)$

were treated with PLE. The results indicated that rutin was quickly absorbed within $42 \mathrm{~min}$ and had minimum $A \cup C_{(0-t)}$ and $C_{\max }$. This was mainly due to the fact that rutin was predominantly in its glycosidic form, so defective absorption and intestinal bacteria degradation occurred in the intestinal tract after oral intake $[29,30]$. The $t_{1 / 2}$ and $\mathrm{T}_{\max }$ of avicularin and quercitrin were similar, due to their similar structural features. However, quercitrin had double absorption maxima at about 300 min which was distinctly observed in the concentration-time curve, possibly due to enterohepatic circulation [31]. Another reason might be that quercitrin undergoes metabolism through phase I hydrolysis to quercetin, and quercetin can be converted to quercetin glucuronide [32]. Furthermore, the possible explanation of the double-site absorption of the drug might be that the first peak was for absorption of the active ingredients in stomach, while the second peak was probably due to intestinal absorption.

This study is the first to report pharmacokinetics of rutin, avicularin and quercitrin after oral administration of PLE in vivo. The pharmacokinetic differences might be due to the complex constituents of plant extracts, which probably led to drug-drug interactions, with impacts on the pharmacokinetic behavior of each component.

\section{CONCLUSION}

A sensitive and selective UHPLC-Q-ExactiveOrbitrap-MS method for the simultaneous determination of rutin, avicularin and quercitrin from parasitic loranthus extract in rat plasma has been developed and validated in this study. These results might be useful in demonstrating possible mechanisms of action of parasitic loranthus. Moreover, the results provide basic understanding of the use of parasitic loranthus in clinical practice.

\section{DECLARATIONS}

\section{Acknowledgement}

This study was supported by National Natural Science Foundation of China (no. 81473368), the Collaborative Innovation Center for Respiratory Disease Diagnosis and Treatment, and the Chinese Medicine Development of Henan Province financial support. We are grateful to Professor Kai Ma for his routine management and careful maintenance of the UHPLC-QExactive-Orbitrap-MS instrument.

\section{Conflict of interest}

No conflict of interest is associated with this work

\section{Contribution of authors}

We declare that this work was done by the authors named in this article and all liabilities pertaining to claims relating to the content of this

Table 5: Pharmacokinetic parameters of rutin, avicularin, quercitrin after oral administration of parasitic loranthus extract $(n=6)$.

\begin{tabular}{lcccccc}
\hline Analyte & $\begin{array}{c}\text { Dose } \\
(\mathbf{m g} / \mathbf{k g})\end{array}$ & $\begin{array}{c}\mathbf{A U C}_{(\mathbf{0 - t})} \\
(\mathbf{m i n}, \mathbf{n g} / \mathbf{m L})\end{array}$ & $\begin{array}{c}\mathbf{M R T}_{(\mathbf{0 - t})} \\
(\mathbf{m i n})\end{array}$ & $\begin{array}{c}\mathbf{t}_{\mathbf{1} / \mathbf{2}} \\
(\mathbf{m i n})\end{array}$ & $\begin{array}{c}\text { Tmax } \\
(\mathbf{m i n})\end{array}$ & $\begin{array}{c}\mathbf{C m a x} \\
(\mathbf{n g} / \mathbf{m L})\end{array}$ \\
\hline Rutin & 3.48 & $1657.00 \pm 200.81$ & $181.64 \pm 10.38$ & $201.88 \pm 41.03$ & $42.50 \pm 6.12$ & $10.35 \pm 1.49$ \\
Avicularin & 4.40 & $6731.36 \pm 573.05$ & $136.67 \pm 5.56$ & $128.46 \pm 14.39$ & $62.50 \pm 14.75$ & $59.16 \pm 7.33$ \\
Quercitrin & 14.96 & $12274.11 \pm 1427.83$ & $171.26 \pm 5.61$ & $128.64 \pm 17.74$ & $65.00 \pm 12.25$ & $80.64 \pm 10.61$ \\
\hline
\end{tabular}


article will be borne by the authors. Ying Cui supervised the experiments and acquired funding for the research. Ling-Ing $\mathrm{Li}$ designed and performed the experiments, and wrote the manuscript. Shu Yang assisted in the experiments. Hong-li Wang and Jing Feng bred rats and collected blood. Kai Ma provided routine management and careful maintenance of the UHPLC Q-Exactive Orbitrap HRMS instrument. De-en Han contributed critical review of the manuscript.

\section{Open Access}

This is an Open Access article that uses a funding model which does not charge readers or their institutions for access and distributed under the terms of the Creative Commons Attribution License (http://creativecommons.org/licenses/by/ 4.0) and the Budapest Open Access Initiative (http://www.budapestopenaccessinitiative.org/rea d), which permit unrestricted use, distribution, and reproduction in any medium, provided the original work is properly credited.

\section{REFERENCES}

1. Chinese Pharmacopoeia Commission. Chinese pharmacopoeia, part 1. Beijing: China Medical Science and Technology Society. 2015; pp 299-300.

2. Zhu KX, Lu D, Pei HH, Zhao MH, Li YH. Study on the distribution in Guangxi and host status of Loranthaceae. Guangxi J Trad Chin Med 2010; 33(2): 59-61.

3. Diego Rubiales, HS Heide Jorgensen. Parasitic plants. Encicl Life Sci 2011; 12: 1-10.

4. Love A. Parasitic Flowering Plants. Economic Botany 1971; 52(1): 194-195.

5. Ameer OZ, Salman IM, Quek KJ, Asmawi MZ. Loranthus ferrugineus: a Mistletoe from Traditional Uses to Laboratory Bench. J Pharmacopuncture 2015; 18(1): 718.

6. Wei S, Ma X, Pan L, Miao J, Fu J, Bai L, Zhang Z, Guan $Y$, Mo $C$, Huang $H$, et al. Transcriptome Analysis of Taxillusi chinensis (DC.) Danser Seeds in Response to Water Loss. PloS One 2017; 12(1): e0169177.

7. Wang Y, Zhang SY, Ma XF, Tian WX. Potent inhibition of fatty acid synthase by parasitic loranthus [Taxillus chinensis (dc.) danser] and its constituent avicularin. $J$ Enzyme Inhib Med Chem 2006; 21(1): 87-93.

8. Tian WX, Zhou ZK, Zhang SY, Deng M, Zhou ZK, Wang $Y$. Parasitic loranthus from Loranthaceae rather than Viscaceae potently inhibits fatty acid synthase and reduces body weight in mice. J Ethnopharmacol 2008; 118(3): 473-478.

9. Li YS, Fu SX, Han Y, Tseng KF. The diuretic action of flavonearabinoside isolated from Chinese drug KwangChi-Sheng Loranthus parasiticus L. Acta Pharm Sin 1959; 7(1): 1-5.
10. Zhang $H$, Huang FY, Liu RY, Lu HL, Su BW, Zhu KX, Li $Y H$. Effects of Taxilli Herba from different hosts on lowering blood pressure of spontaneously hypertensive rats. Chin Trad Pat Med 2018; 40(2): 249-254.

11. Uzochukwu IC, Osadebe PO. Comparative evaluation of antidiabetic activities of Flavonoids extract and crude methanol extract of loranthus Micranthus parasitic on. $J$ Pharm Allied Sci 2009; 4(1): 108-118.

12. Osadebe PO. Seasonal variation for the antidiabetic activity of Loranthus micranthus methanol extract. Asian Pac J Trop Med 2010; 3(3): 196-199.

13. Nagar $H$, Tiwari DK, Dwivedi G, Tripathi RK, Singh $P$. Protective effect of loranthus longiflorus on learning and memory of rats exposed to electromagnetic radiation (EMR). Int Res J Pharm 2013; 4(5): 194-197.

14. Sakurai A, Okumura Y. Chemical studies on the mistletoe. $V$. The structure of taxillusin, a new flavonoid glycoside isolated from Taxillus kaempferi. Bull Chem Soc Jpn 1983; 56(2): 542-544.

15. Tseng KF, Cheng CL. Studies on the flavonoids in Chinese drug. The isolation of flavonearabinoside from Kwang-Chi-Sheng. Acta Pharm Sin 1953; 5(2): 317-325.

16. Ding B, Dai Y, Hou YL, Wu XM, Chen X, Yao XS. Four new hemiterpenoid derivatives from Taxillus chinensis. Fitoterapia 2013; 86: 1-5.

17. Li LL, Wang J, Cui Y, Wen P, Guan J, Yang S, Ma K. Antirheumatic substance and meridian tropism of Loranthus parasiticus based on "syndrome-efficacyanalysis of biological samples". Chin J Chin Mater Med 2016; 41(10): 1933-1939.

18. Zhao HW, Wang J, Cui Y, Wang HJ, Wang JM, Ma K. A Research of Effective Chemicals of Taxillus Chinensis Danser on Osteoporosis and Channel Tropism Based on Disease-Effect-Bioanalysis. Modern Trad Chin Med Mater Medica-World Sci Tech 2016; 18(4): 626-631.

19. Chen X, Wang Z, Zhang F, Zhu L, Li Y, Xia Y. Determination of rutin on the poly ( $p$-aminobenzene sulfonic acid) modified glassy carbon electrode. Chem Pharm Bull (Tokyo) 2010; 58 (4): 475-478.

20. Wang $Y$, Zhang SY, Ma XF, Tian WX. Potent inhibition of fatty acid synthase by parasitic loranthus [Taxillus chinensis (DC.) Danser] and its constituent avicularin. J Enzyme Inhib Med Chem 2006; 21(1): 87-93.

21. Huang $Y$, Zhang $P$, He F, Zheng L, Wang $Y L$, Wu JZ. Simultaneous determination of four bioactive flavonoids from Polygonum orientale $L$. in dog plasma by UPLCESI-MS/MS and application of the technique to pharmacokinetic studies. J Chromatogr B Analyt Technol Biomed Life Sci 2014; 957: 96-104.

22. He J, Song L, Zhou GY, Zhao LW, Correction to: The Rapid Analysis of Antibiotics in Animal Meat and Egg Using a Novel SEP Method and UPLC-MS/MS. Chromatographia 2017; 80(9): 1329-1342.

23. Yao F, Wang JM, Chen J, Zhang $H$, Qian MR, Zeng $Y H$, Xia $W, L u Y Q$. Efficient Detection of $\alpha$-, $\beta$-, and $\gamma$ Hexabromocyclododecane Isomers and Their Hydroxylated Metabolites in Poultry Tissues Based on Dispersive Solid Phase Extraction Using an Enhanced

Trop J Pharm Res, October 2019; 18(10):2181 
Lipid-Removing Material Combined with UPLC-MS/MS Food Anal Method 2018; 11(1): 251-259.

24. Huang Y, Sun HY, Qin XL, Li YJ, Liao SG, Gong ZP, Lu $Y$, Wang $Y L$, Wang AM, Lan YY, et al. A UPLC-MS/MS Method for Simultaneous Determination of Free and Total Forms of a Phenolic Acid and Two Flavonoids in Rat Plasma and Its Application to Comparative Pharmacokinetic Studies of Polygonum capitatum Extract in Rats. Molecules 2017; 22(3): 1-13.

25. Wu J, Xie Yi, Xiang Z, Wang CJ, Zhou H, Liu L. Simultaneous Determination of Multiple Components in Guanjiekang in Rat Plasma via the UPLC-MS/MS Method and Its Application in Pharmacokinetic Study. Molecules 2016; 21(12): 1732-1714.

26. Kim NY, Shin YJ, Park SJ, Yoo G, Kim YJ, Yoo H.H, Kim $\mathrm{SH}$. Simultaneous Determination of Six Compounds in Hedera helix L. Using UPLC-ESI-MS/MS. Chromatographia 2017; 80(7): 1025-1033.

27. National Research Council (US) Committee for the Update of the Guide for the Care and Use of Laboratory Animals. Guide for the Care and Use of Laboratory Animals.8th edition. Washington (DC): National Academies Press (US); 2011.
28. Zhi Sun, Longshan Zhao, Lihua Zuo, Chao Qi, Pan Zhao, Xiaohong Hou. A UHPLC-MS/MS method for simultaneous determination of six flavonoids, gallic acid and 5,8-dihydroxy-1,4-naphthoquinone in rat plasma and its application to a pharmacokinetic study of Cortex Juglandis Mandshuricae extract. J Chromatogr B Analyt Technol Biomed Life Sci 2014; 958: 55-62.

29. Carbonaro M, Grant G. Absorption of quercetin and rutin in rat small intestine. Ann Nutr Metab 2005; 49(3): 178182.

30. Manach C, Morand C, Demigne C, Texier O, Regerat $F$, Remesy $C$. Bioavailability of rutin and quercetin in rats. Febs Letters 1997; 409(1): 12-16.

31. Wang X, Zhao X, Gu L, Lv C, He B, Liu Z, Hou P, Bi K, Chen $X$. Simultaneous determination of five free and total flavonoids in rat plasma by ultra hplc-ms/ms and its application to a comparative pharmacokinetic study in normal and hyperlipidemic rats. J Chromatogr B. 2014; 953-954: 1-10.

32. Qin XL, Sun HY, Yang W, Li YJ, Zheng L, Liu T, Huang $Y$. Analysis of metabolites of quercitrin in rat intestinal flora by using UPLC-ESI-Q-TOF-MS/MS. Zhongguo Zhong Yao Za Zhi. 2017; 42(2): 357-362. 